\title{
Fluoroethylene Carbonate and Vinylene Carbonate Reduction: Understanding Lithium-ion Battery Electrolyte Additives and Solid Electrolyte Interphase Formation
}

\author{
Alison L. Michan ${ }^{\dagger}$ Bharathy. S. Parimalam ${ }^{\ddagger}$ Michal Leskes, ${ }^{\dagger}$ Rachel N. \\ Kerber ${ }^{\dagger}$ Taeho Yoon $^{\ddagger}{ }^{\ddagger}$ Clare P. Grey, ${ }^{\dagger}$ and Brett L. Lucht ${ }^{*, \ddagger}$ \\ Department of Chemistry, University of Cambridge, Lensfield Road, Cambridge, CB2 \\ $1 E W$, United Kingdom, and University of Rhode Island, Kingston, RI 02881
}

E-mail: blucht@chm.uri.edu

\begin{abstract}
We have synthesized the reduction products of fluoroethylene carbonate (FEC) and vinylene carbonate (VC) via lithium naphthalenide reduction. By analyzing the resulting solid precipitates and gas evolution, our results confirm that both $\mathrm{FEC}$ and $\mathrm{VC}$ decomposition products include $\mathrm{HCO}_{2} \mathrm{Li}$, $\mathrm{Li}_{2} \mathrm{C}_{2} \mathrm{O}_{4}, \mathrm{Li}_{2} \mathrm{CO}_{3}$, and polymerized VC. For FEC, our experimental data supports a reduction mechanism where $\mathrm{FEC}$ reduces to form $\mathrm{VC}$ and $\mathrm{LiF}$, followed by subsequent $\mathrm{VC}$ reduction. In the $\mathrm{FEC}$ reduction product, $\mathrm{HCO}_{2} \mathrm{Li}, \mathrm{Li}_{2} \mathrm{C}_{2} \mathrm{O}_{4}$, and $\mathrm{Li}_{2} \mathrm{CO}_{3}$ were found in smaller quantities than in the $\mathrm{VC}$ reduction product, with no additional fluorine environments being detected by solid-state nuclear magnetic resonance or X-ray photoelectron spectroscopy analysis. With these additives being practically used in higher (FEC) and lower (VC) concentrations in the base electrolytes of lithium-ion batteries, our results suggest that the different relative ratios of the inorganic and organic reduction products formed by their decomposition may be relevant to the chemical composition and morphology of the solid electrolyte interphase formed in their presence.
\end{abstract}

\section{Introduction}

Additives are widely used to improve performance of Liion batteries, offering an economically viable method of performance enhancement compatible with existing manufacturing infrastructure. ${ }^{1}$ Generally, the function of additives is sacrificial: they are reduced at different voltage potentials compared to the base electrolytes to which they are added, forming decomposition products that are incorporated into a protective layer on electrodes. ${ }^{1-5}$ This protective layer is called the solid electrolyte interphase (SEI). ${ }^{6,7}$ The formation of a stable $\mathrm{SEI}$ is essential for all Li-ion batteries, preventing further electrolyte decomposition, thereby underlying capacity retention. ${ }^{1,5-8}$ The SEI also represents an electronically insulating barrier between the electrodes and electrolyte, with its composition, thickness, and structure influencing the lithium transport across the interphase. ${ }^{9,10}$ The performance enhancement achieved by the use of additives in the base electrolyte of Li-ion batteries is therefore linked to the chemical species formed in their decomposition which are incorporated into the SEI. A fundamental understanding of how specific additives improve and alter the SEI would allow further insight into favourable SEI properties.

Two additives that have been widely studied include fluoroethylene carbonate (FEC) and vinylene carbonate (VC). These additives have been used with electrode materials including $\mathrm{Si}$, improving capacity retention. ${ }^{5,11-18}$ Although it is widely accepted that these additives improve performance, there remains some debate regarding their decomposition mechanisms and the resulting SEI. It is believed that one key aspect of their favourable SEI formation is due to their decomposition into semicarbonate or organic species. ${ }^{1,4,19-23}$ Theoretical predictions indicate FEC and VC may yield very similar reduction products, ${ }^{24-26}$ and a key difference between these additives is thought to relate to $\mathrm{LiF}$ as a major species in the presence of FEC. ${ }^{13,27,28}$ Typical concentrations achieving performance enhancement differ, with $\mathrm{VC}$ used in lower concentrations of approximately $2-5 \%$ compared with FEC that can be used in higher concentrations up to $50 \%$ FEC. ${ }^{1,5,16,18,29}$

Practically, the SEI layer is extremely airsensitive. ${ }^{30,31}$ Moreover, with a thickness of less than $100 \mathrm{~nm}$ it is very difficult to study experimentally. Here, our strategy is to synthesize the reduction products of FEC and VC in order to experimentally confirm their 
reduction products. Lithium naphthalenide (Li-Nap), a well-known reducing agent, is known to react with solvents in a similar manner to those which may occur on lithiated anodes. ${ }^{32}$ It is used here to reduce FEC and VC, modelling a reduction process in a similar manner to that which may occur in a lithium-ion battery. Solid products are analyzed with X-ray photoelectron spectroscopy (XPS), solid-state NMR (ssNMR), and Fourier transform infrared spectroscopy (FTIR). Gas evolution is monitored using gas chromatography mass spectrometry (GC-MS). The many techniques provide chemical signatures for future work. Viable reactions to form the detected decomposition products are proposed. For FEC, we propose a reduction scheme where FEC reduces to form $\mathrm{LiF}$ and $\mathrm{VC}$, followed by further reduction of $\mathrm{VC}$ to polymerized $\mathrm{VC}$ (poly $(\mathrm{VC})$ ). The poly(VC) contains repeating EC units joined by crosslinking sites; our analysis shows no evidence for F-C bonds in the polymer. $\mathrm{HCO}_{2} \mathrm{Li}, \mathrm{Li}_{2} \mathrm{C}_{2} \mathrm{O}_{4}$, and $\mathrm{Li}_{2} \mathrm{CO}_{3}$, are also found in small quantities. For VC, we detect lithium environments of $\mathrm{HCO}_{2} \mathrm{Li}, \mathrm{Li}_{2} \mathrm{C}_{2} \mathrm{O}_{4}$, and $\mathrm{Li}_{2} \mathrm{CO}_{3}$, in addition to poly (VC).

\section{Methods}

Synthesis. All reagents were used as obtained, without further purification. Battery-grade $\mathrm{VC}$ and FEC were obtained from BASF. Naphthalene (99+\%, Scintillation grade) and THF (Anhydrous, 99.9\%) were purchased from Acros organics. Lithium discs were obtained from MTI Corporation. Preparation of the reducing agent and the reduction reaction were carried out inside a nitrogen-filled glovebox. Li-Nap $(0.546 \mathrm{M})$ solution in THF was prepared with $10 \mathrm{~mol} \%$ excess naphthalene. Lithium foils were added to naphthalene solution of THF and stirred overnight at room temperature. The solution turned green in a few minutes after the addition of lithium metal and became dark green after stirring overnight.

$1.52 \mathrm{~g}$ of FEC was reduced with 1 molar equivalent of Li-Nap. The solution turned yellowish brown immediately and left under stirring overnight. The overhead gas was analyzed using GC-MS Precipitate was separated with centrifugal separation and washed with diethyl ether. It was further dried under vacuum overnight at room temperature and produced $1.44 \mathrm{~g}$ of light yellow powder.

$1.24 \mathrm{~g}$ of $\mathrm{VC}$ was reduced with 1 molar equivalent of Li-Nap. The solution turned dark brown immediately and left under stirring overnight. The overhead gas was analyzed using GC-MS. Precipitate was separated with centrifugal separation and washed with diethyl ether. It was further dried under vacuum overnight at room temperature and produced $1.50 \mathrm{~g}$ of brown powder.

The synthesis was performed using both deuterated and nondeuterated naphthalene yielding two sets of samples.

XPS. XPS spectra of the dried precipitates were acquired using a thermo scientific K-alpha XPS instrument. Samples were made into circular pellets with a press and transferred from the glovebox to the XPS chamber using a vacuum transfer module without exposure to air. $\mathrm{C} 1 \mathrm{~s}, \mathrm{O} 1 \mathrm{~s}$ and $\mathrm{Li} 1 \mathrm{~s}$ spectra were obtained from the VC precipitate, whereas C 1s, O 1s, Li 1s and F1s spectra were acquired from the FEC precipitate. An Argon flood gun was used to avoid surface charge accumulation during sample analysis. The binding energy was corrected based on the $\mathrm{C} 1 \mathrm{~s}$ of hydrocarbon at $284.8 \mathrm{eV}$. The data was processed and analyzed using the Thermo Avantage XPS Peak 4.1 and the Origin software.

ssNMR. Multinuclear ssNMR spectra were obtained on 16.4 T Bruker Avance III $700 \mathrm{MHz}$ and $11.7 \mathrm{~T}$ Bruker Avance III $500 \mathrm{MHz}$ spectrometers. Samples were packed in an Ar glovebox (typically $\mathrm{O}_{2}$ and $\mathrm{H}_{2} \mathrm{O}<0.1 \mathrm{ppm}$ ), avoiding any exposure to ambient air, into rotors of $1.3 \mathrm{~mm}, 3.2 \mathrm{~mm}$, and $4 \mathrm{~mm}$ outer diameters. Magic-angle spinning (MAS) frequencies ranged from $10 \mathrm{kHz}$ to $60 \mathrm{kHz}$, spinning under $\mathrm{N}_{2} .{ }^{1} \mathrm{H}$ and ${ }^{13} \mathrm{C}$ chemical shifts were externally referenced to adamantane $\left({ }^{1} \mathrm{H} 1.9 \mathrm{ppm},{ }^{13} \mathrm{C}\right.$ $\left.38.5 \mathrm{ppm}, \mathrm{CH}_{2}\right)$, and ${ }^{7} \mathrm{Li}$ and ${ }^{19} \mathrm{~F}$ to $\mathrm{LiF}\left({ }^{7} \mathrm{Li}-1 \mathrm{ppm},{ }^{19} \mathrm{~F}-204\right.$ $\mathrm{ppm}) .{ }^{33,34}$ The data were processed using the Bruker TOPSPIN software and analyzed using the dmfit software. ${ }^{35}$ Typical radio frequency (RF) field strengths used were $\left({ }^{1} \mathrm{H}\right) 90-100 \mathrm{kHz},\left({ }^{7} \mathrm{Li}\right)$ $80-125 \mathrm{kHz},\left({ }^{19} \mathrm{~F}\right) 80-125 \mathrm{kHz}$, and $\left({ }^{13} \mathrm{C}\right) 80-120 \mathrm{kHz}$.

Each of the FEC and VC precipitates were investigated using ${ }^{1} \mathrm{H},{ }^{7} \mathrm{Li}$, and ${ }^{19} \mathrm{~F}$ ssNMR, using $1.3 \mathrm{~mm}$ rotors and $60 \mathrm{kHz}$ spinning frequency. ${ }^{13} \mathrm{C}$ ssNMR experiments were performed using larger $3.2 \mathrm{~mm}$ and $4 \mathrm{~mm}$ rotors and spinning frequencies ranging from 10 to $12 \mathrm{kHz}$. The larger samples provided greater sensitivity. The ${ }^{13} \mathrm{C}$ spectra were acquired using swept-frequency twopulse phase modulation (swfTPPM) ${ }^{36}{ }^{1}{ }^{1} \mathrm{H}$ decoupling at 80-100 $\mathrm{kHz}$. Direct excitation ${ }^{13} \mathrm{C}$ experiments provided quantitative information. ${ }^{1} \mathrm{H}_{-}{ }^{13} \mathrm{C},{ }^{7} \mathrm{Li}_{-}{ }^{13} \mathrm{C}$, and ${ }^{19} \mathrm{~F}-{ }^{13} \mathrm{C}$ correlation experiments were used to probe spatial proximity of these nuclei by transferring magnetization from ${ }^{1} \mathrm{H},{ }^{7} \mathrm{Li}$, and ${ }^{19} \mathrm{~F}$ nuclei by cross polarization to ${ }^{13} \mathrm{C}$ nuclei. Dipolar dephasing (interrupted decoupling) ${ }^{1} \mathrm{H}-{ }^{13} \mathrm{C}$ cross polarization experiments allowed differentiation between protonated and non-protonated environments. ${ }^{34,37}$ Further ssNMR experimental details are given in the Supporting Information.

FTIR. FTIR analysis was performed on each of the precipitates prepared with non-deuterated naphthalene. FTIR spectra of the dried precipitates were acquired on a Bruker Tensor 27 spectrometer, equipped with germanium crystal, in attenuated total reflectance (IR-ATR) mode. Samples were transferred using air-tight vials and the spectrometer was operated inside a nitrogen filled glovebox to avoid sample exposure to ambient air. Each spectrum was acquired with 128 scans from $700 \mathrm{~cm}^{-1}$ to $4000 \mathrm{~cm}^{-1}$ at the spectral resolution of $4 \mathrm{~cm}^{-1}$. The data was processed and analyzed using the OPUS and Origin software.

GC-MS analysis of gases. The analysis of evolved gases during the reaction was performed on thermo trace GC-Ultra equipped with Agilent poroplot amines column and a mass selective detector-ISQ. Gas analysis was performed by evacuating the head space of the reaction flask with a $10 \mu \mathrm{L}$ GC syringe. Helium was used as carrier gas at a flow rate of $1.5 \mathrm{~mL} / \mathrm{min}$. The initial column temperature was $50{ }^{\circ} \mathrm{C}$, and the temperature was ramped at $10{ }^{\circ} \mathrm{C} / \mathrm{min}$ to $220{ }^{\circ} \mathrm{C}$ and held at that temperature for $20 \mathrm{~min}$ with the total run time of $37 \mathrm{~min}$. The mass spectra obtained on these gases were compared to the NIST library to determine their molecular structures.

Dilute reduction reactions. $8.00 \mathrm{~mL}$ of $0.273 \mathrm{M} \mathrm{FEC} \mathrm{in}$ THF was stirred vigorously and $1.00 \mathrm{~mL}$ of $0.546 \mathrm{M}$ Lithium naphthalenide solution in THF was added drop by drop to the solution at room temperature. The dark green color of the lithium naphthalenide disappeared instantaneously as it contacted the FEC solution and the reaction mixture turned turbid yellow from clear and colorless. The reaction mixture was analyzed with Agilent 6890-5973N GC equipped with an Agilent 5973N mass selective detector. Helium was used a carrier gas at a flow rate of 24 $\mathrm{mL} / \mathrm{min}$. The initial column temperature was $40^{\circ} \mathrm{C}$, and the temperature was ramped at $10^{\circ} \mathrm{C} / \mathrm{min}$ to $200^{\circ} \mathrm{C}$ and held at that temperature for 2 minutes with the total run time of 18 minutes. The mass spectra obtained were compared to the NIST library to determine their molecular structures.

Computational Methods. Chemical shifts were calculated using density functional theory (DFT) using Gaussian $09^{38}$ and estimated using ChemNMR implemented in ChemBioDraw 13.0, see Supporting Information Table S1. ChemNMR approximates ${ }^{13} \mathrm{C}$ and ${ }^{1} \mathrm{H}$ chemical shifts with respect to TMS. For all DFT calculations the hybrid functional B3LYP 39,40 and $6-311 \mathrm{G}++(\mathrm{d}, \mathrm{p})$ basis set were used, ${ }^{41,42}$ in combination with tight convergence. Frequency calculations were performed to confirm ground state convergence. The absolute NMR shift values were referenced to adamantane and $\mathrm{LiF}$ as in the experiment. Further computational details are given in the Supporting Information.

\section{Results}

XPS. The chemical composition of the FEC and VC precipitates is first examined by XPS, with Figure 1 showing the XPS spectra of C1s, O1s, and F1s for each 

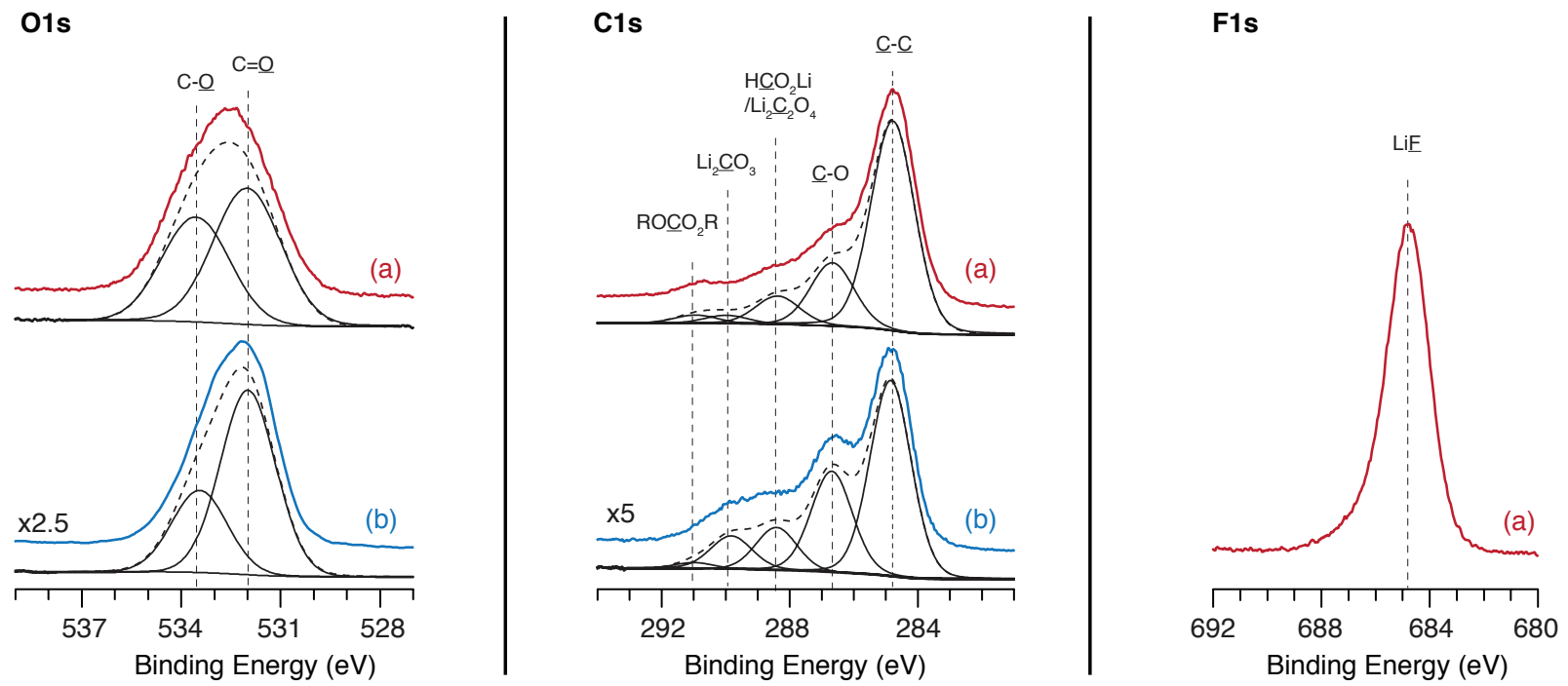

Figure 1: XPS spectra of the (a) FEC and (b) VC precipitates obtained through reduction of FEC and VC using deuterated naphthalene. Deconvolutions of the spectra are shown in black.

of the FEC and VC precipitates. The relative elemental concentrations of the FEC and VC precipitates are summarized in Table 1 and show that the FEC precipitate contains smaller relative quantities of species containing $\mathrm{C}$ and $\mathrm{O}$ than the $\mathrm{VC}$ precipitate. Results from previous XPS studies of the SEI, ${ }^{18,32,43-45}$ and potential products identified in theoretical studies of the reduction reactions, ${ }^{20,24-26}$ are used to help assign the XPS spectra. We note that the residual naphthalene and THF in the system may contribute to the overall signal seen in the $\mathrm{C} 1 \mathrm{~s}$ spectra $(\mathrm{C}=\mathrm{C}, \mathrm{C}-\mathrm{C}$, and $\mathrm{C}-\mathrm{O})$.

Table 1: Relative elemental concentrations from XPS analysis.

\begin{tabular}{lll}
\hline Element & FEC Precipitate & VC Precipitate \\
\hline O1s & $16 \%$ & $35 \%$ \\
C1s & $41 \%$ & $52 \%$ \\
Li1s & $27 \%$ & $12 \%$ \\
F1s & $16 \%$ & - \\
\hline
\end{tabular}

F1s Core Peaks: For the FEC precipitate, the dominant peak at $684.8 \mathrm{eV}$ in the $\mathrm{F} 1 \mathrm{~s}$ spectrum is assigned to LiF. The asymmetry of the peak, extending to $689 \mathrm{eV}$ suggests the possibility of a minor additional fluorine environment but a more distinct shoulder at approximately $688 \mathrm{eV}$ would be expected if significant amounts of either residual FEC or a fluorinated organic species was present. ${ }^{29,46}$ This XPS assignment is further confirmed by ${ }^{19} \mathrm{~F}$ ssNMR (discussed later).

C1s Core Peaks: For both the FEC and VC precipitates, the deconvolutions of the spectra show peaks at approximately $291.0 \mathrm{eV}, 290.0 \mathrm{eV} 288.5 \mathrm{eV}, 286.8 \mathrm{eV}$, and $284.8 \mathrm{eV}$, the relative intensities of these peaks differing between the samples. Based on the binding energies, the $291.0 \mathrm{eV}$ peak is assigned to $\mathrm{ROCO}_{2} \mathrm{R}$ and the $290.0 \mathrm{eV}$ peak to $\mathrm{Li}_{2} \mathrm{CO}_{3} .{ }^{21,44}$ The peak at $288.5 \mathrm{eV}$ is assigned to $\mathrm{CO}_{2}$ environments contained in $\mathrm{HCO}_{2} \mathrm{Li}$ and/or $\mathrm{Li}_{2} \mathrm{C}_{2} \mathrm{O}_{4}$, while the peaks at lower binding energies of $286.8 \mathrm{eV}$ and $284.8 \mathrm{eV}$ indicate $\mathrm{C}-\mathrm{O}$ and $\mathrm{C}-\mathrm{C}$ bonds, respectively. $\mathrm{Li}_{2} \mathrm{CO}_{3}$ has a larger contribution in the $\mathrm{VC}$ precipitate compared with the FEC precipitate, also seen by ${ }^{7} \mathrm{Li}$ and ${ }^{13} \mathrm{C}$ ssNMR later. In addition, the relative signal intensity of the $\mathrm{HCO}_{2} \mathrm{Li} / \mathrm{Li}_{2} \mathrm{C}_{2} \mathrm{O}_{4}$ peak is larger in the $\mathrm{VC}$ precipitate, these carboxylate environments being confirmed by ${ }^{13} \mathrm{C}$ ssNMR in the $\mathrm{VC}$ sample, discussed further. The combination of the $291.0 \mathrm{eV}\left(\mathrm{ROCO}_{2} \mathrm{R}\right)$ peak and larger contribution at $286.8 \mathrm{eV}(\mathrm{C}-\mathrm{O})$ indicate alkyl carbonate environments, these environment being previously assigned to poly(VC). ${ }^{21,45,47-49}$

O1s Core Peaks: For the FEC precipitate, the dominant peak is centred at $532.8 \mathrm{eV}$, characteristic of a mixture of $\mathrm{C}=\mathrm{O}$ and $\mathrm{C}-\mathrm{O}$ environments. In contrast, the VC precipitate shows a central peak centred at 532 $\mathrm{eV}$ assigned to a carbonate contained in $\mathrm{Li}_{2} \mathrm{CO}_{3}$, alkyl carbonate and/or carboxylate contained in $\mathrm{HCO}_{2} \mathrm{Li}$ or $\mathrm{Li}_{2} \mathrm{C}_{2} \mathrm{O}_{4}$. The shift between the FEC and VC spectra indicates different relative quantities of local $\mathrm{O}$ environments contained in the samples, the shift towards lower binding energy in the $\mathrm{VC}$ precipitate consistent with the $\mathrm{C} 1 \mathrm{~s}$ spectrum indicating larger relative amounts of $\mathrm{Li}_{2} \mathrm{CO}_{3}$.

\section{Solid State NMR.}

Multinuclear ssNMR: Direct excitation ${ }^{1} \mathrm{H},{ }^{7} \mathrm{Li}$, and ${ }^{19} \mathrm{~F}$ multinuclear ssNMR measurements of the FEC and VC precipitates (Figure 2) were performed. The ${ }^{1} \mathrm{H}$ ssNMR spectra both show similar overlapping resonances with shifts of $1.5,3.6,4.6 / 4.8 \mathrm{ppm}$. These resonances are more easily assigned using the additional information and larger chemical shift dispersion provided by ${ }^{13} \mathrm{C}$ ssNMR experiments (discussed further). The VC sample shows a minor resonance at $8.3 \mathrm{ppm}$. This distinctive shift is consistent with an assignment of $\mathrm{HCO}_{2} \mathrm{Li}$ or similar environment based on previous work by Leskes et al. ${ }^{50}$ We note that residual THF may contribute to the signals of 1.5 and $3.6 \mathrm{ppm}$. In the ${ }^{7} \mathrm{Li}$ ssNMR spectra, each of the samples show a resonance near 0 ppm, the signal being consistent with the presence of $\mathrm{Li}_{2} \mathrm{CO}_{3}, \mathrm{Li}_{2} \mathrm{C}_{2} \mathrm{O}_{4}$, and $\mathrm{HCO}_{2} \mathrm{Li}$. The assignment is based on both previous ${ }^{7} \mathrm{Li}$ ssNMR measurements of 

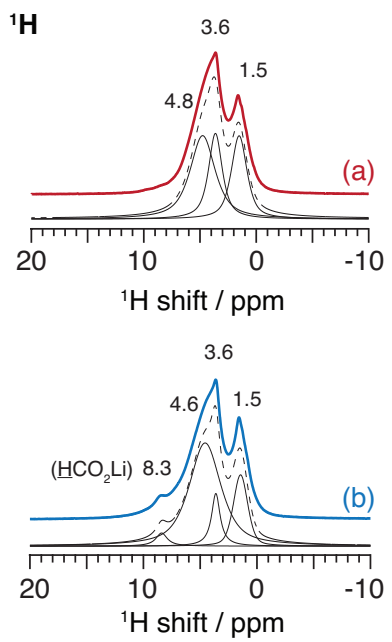

${ }^{7} \mathbf{L i}$
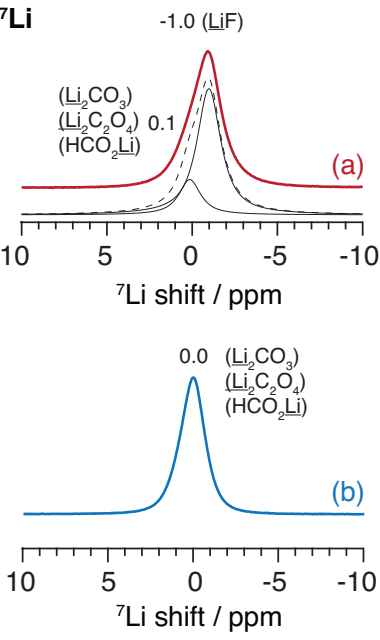

${ }^{19} \mathrm{~F}$

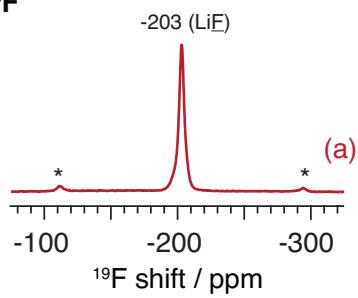

Figure 2: ssNMR spectra of the precipitates obtained through reduction of (a) FEC and (b) VC using deuterated naphthalene. ${ }^{1} \mathrm{H}$ Hahn echo, ${ }^{7} \mathrm{Li}$ single pulse, and ${ }^{19} \mathrm{~F}$ Hahn echo ssNMR experiments were performed. The spectra were acquired with $60 \mathrm{kHz} \mathrm{MAS}$ and are scaled by maximum signal height. A simulated fit and deconvolution are presented under the experimentally obtained spectra. The asterisks in the ${ }^{19} \mathrm{~F}$ spectrum indicate ssNMR spinning sidebands.

lithium salts ${ }^{50,51}$ and the ${ }^{13} \mathrm{C}$ ssNMR results of this study. In the FEC precipitate, ${ }^{19} \mathrm{~F}$ (-203 ppm) and ${ }^{7} \mathrm{Li}(-1.0 \mathrm{ppm})$ resonances clearly indicate the presence of $\mathrm{LiF}$. No additional resonances are seen in the ${ }^{19} \mathrm{~F}$ spectrum. In contrast to the XPS spectrum, the larger chemical shift dispersion of the ${ }^{19} \mathrm{~F}$ ssNMR spectrum allows for a definitive assignment of any ${ }^{19} \mathrm{~F}$ environments; the ssNMR result here is consistent with the XPS assignment of LiF in the F1s spectrum.

${ }^{13} \mathrm{C}$ ssNMR of FEC precipitates: For the FEC precipitate, direct excitation ${ }^{13} \mathrm{C}$ ssNMR experiments (Figure 3a-i) show relative quantities of carbon environments, labelled $\mathrm{C}$ through $\mathrm{F}$. The large chemical shift dispersion allows for definitive assignments based on chemical shifts, with the labelled ${ }^{13} \mathrm{C}$ spectral peaks summarized in Table 2. Resonance C (155 ppm) is characteristic of a $\mathrm{ROCO}_{2} \mathrm{R}$ carbonate environment (also seen in the C1s XPS spectra). Resonance D (100 ppm) is assigned to a protonated $\mathrm{C}$ environment, adjacent to two OR groups. Resonance E (74 ppm) is assigned to a protonated $\mathrm{C}$ environment adjacent to a single $\mathrm{O}$. Resonance $\mathrm{F}$ (40 ppm) is characteristic of an environment with $\mathrm{C}$ not adjacent to $\mathrm{O}$ and is assigned to $\mathrm{R} \underline{\mathrm{CH}} \mathrm{H}_{2} \mathrm{R}$, its broad linewidth being characteristic of a distribution of similar environments. Resonances assigned to residual naphthalene and THF are labelled. Additional experiments (see Supporting Information) were performed at two different magic angle spinning frequencies $(10 \mathrm{kHz}$, $12 \mathrm{kHz})$ and field strengths $(500,700 \mathrm{MHz})$ to confirm the spinning sideband peak positions. These peaks are indicated by asterisks and do not represent distinct resonances.

The ${ }^{19} \mathrm{~F}-{ }^{13} \mathrm{C}$ cross polarization experiment, Figure 3a-ii, is used to identify chemical environments where ${ }^{19} \mathrm{~F}$ and ${ }^{13} \mathrm{C}$ are in close spatial proximity: the ssNMR experiment uses through-space magnetization transfer from the former to the latter. Interestingly, only a low intensity resonance (E) at approximately $74 \mathrm{ppm}$ is seen in the ${ }^{19} \mathrm{~F}-{ }^{13} \mathrm{C}$ cross polarization experiment (Figure 3a- ii): no peaks are observed in the region of $110 \mathrm{ppm}$ where a $\mathrm{C}-\mathrm{F}$ group may be expected to resonate. The ${ }^{13} \mathrm{C}$ results are consistent with the ${ }^{19} \mathrm{~F}$ ssNMR and $\mathrm{F} 1 \mathrm{~s}$ XPS results showing a single resonance assigned to LiF. The signal detection of resonance $\mathrm{E}$ indicates $\mathrm{LiF}$ is in close proximity to this $\mathrm{C}$ environment. $\mathrm{A}{ }^{7} \mathrm{Li}^{-13} \mathrm{C}$ experiment was also attempted but no signal was detected: the null result is in agreement with the ${ }^{7} \mathrm{Li}$ ssNMR assignment (Figure 2) showing that very little $\mathrm{Li}_{2} \mathrm{CO}_{3}$ (or similar environment resonating near $0 \mathrm{ppm}$ in the ${ }^{7} \mathrm{Li}$ spectrum) is present in the FEC precipitate.

${ }^{1} \mathrm{H}-{ }^{13} \mathrm{C}$ cross polarization experiments, Figures 3aiii, were performed, further confirming the ${ }^{13} \mathrm{C}$ assignments. The signal intensity in these experiments depend on molecular dynamics, mobility, and spatial proximity of ${ }^{1} \mathrm{H}$ and ${ }^{13} \mathrm{C}$ nuclei. Following a similar strategy used in our previous paper to assign different carbon local environments, ${ }^{52}$ a delay time is introduced following the cross polarization step in the experiment to perform a dipolar dephasing (interrupted decoupling) experiment, the experimental details being described in the Supporting Information. When the delay times are varied in the experiment, different $\mathrm{C}$ functional groups can be identified based on their attenuation rates. Protonated $\mathrm{C}$ are attenuated more rapidly than non-protonated $\mathrm{C}$. Also, the signal intensities for rigid $\mathrm{CH} / \mathrm{CH}_{2}$ environments attenuate more rapidly than signal from mobile species such as rotating $\mathrm{CH}_{3}$ methyl groups (due to a reduced dipolar coupling). The results of the experiments here confirm the assignment of resonance $\mathrm{C}$ to $\mathrm{ROCO}_{2} \mathrm{R}$, a species that does not have directly bonded protons, and is not attenuated in the relatively short delays used in the experiment. In contrast, each of the resonances $\mathrm{D}, \mathrm{E}$, and $\mathrm{F}$ show pronounced attenuation, these resonances decaying at similar rates (with increased dephasing delay times) confirming that they correspond to $\underline{C} \mathrm{H}$ and $\underline{C} \mathrm{H}_{2}$ groups.

${ }^{13} \mathrm{C} s N M R$ of $V C$ precipitates: For the VC precipitate, direct excitation ${ }^{13} \mathrm{C}$ ssNMR experiments (Figure 

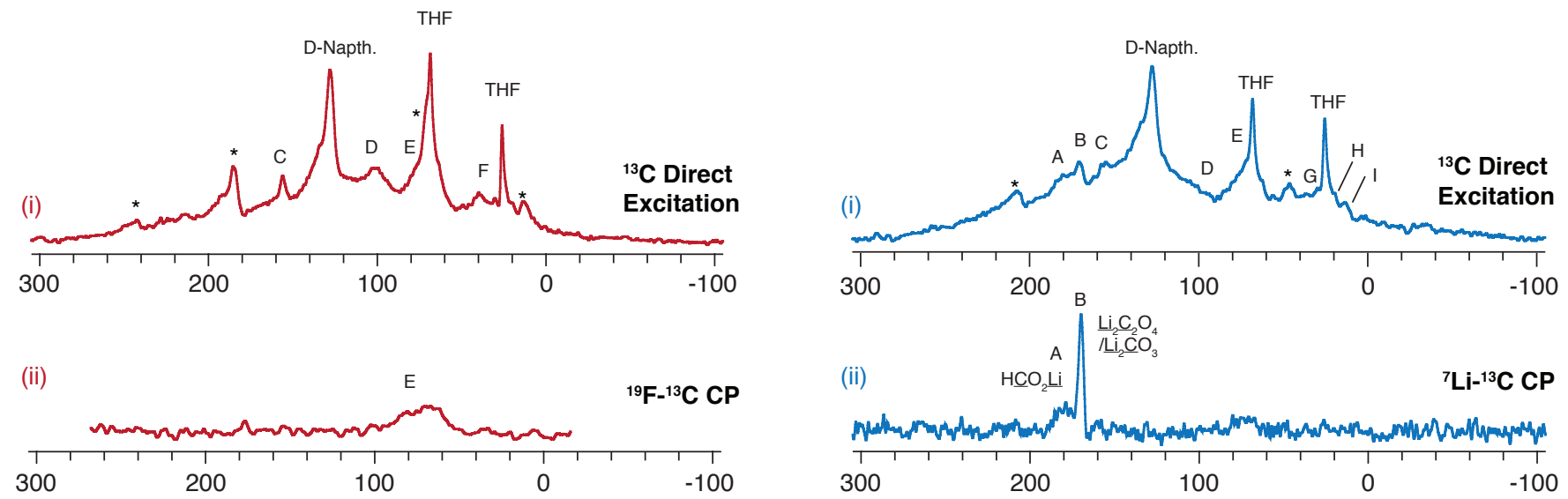

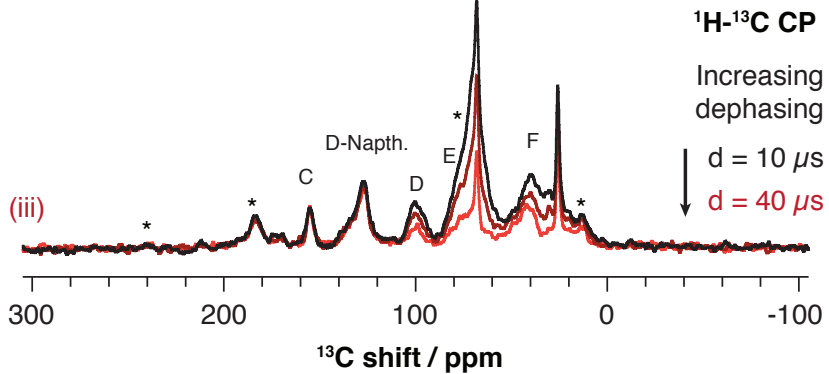

(a) FEC Precipitate

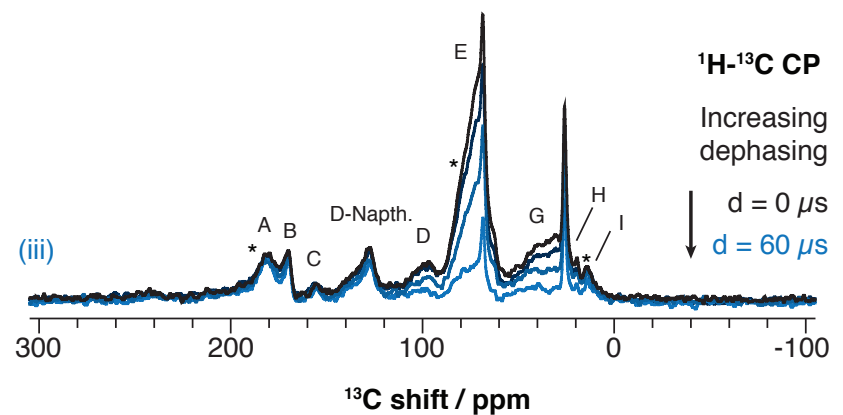

(b) VC Precipitate

Figure 3: ${ }^{13} \mathrm{C}$ ssNMR experiments performed on (a) FEC and (b) VC precipitates. (a-i) ${ }^{13} \mathrm{C}$ single pulse, (a-ii) ${ }^{19} \mathrm{~F}-{ }^{13} \mathrm{C}$ cross polarization, CP, with contact time of $1000 \mu \mathrm{s}$ (a-iii) dipolar dephasing (interrupted decoupling) contact time of $1000 \mu \mathrm{s}$ and interrupted delay times, $\mathrm{d}=40$, 20, and $10 \mu \mathrm{s}$. (b-i) ${ }^{13} \mathrm{C}$ single pulse, (b-ii) ${ }^{7} \mathrm{Li}-{ }^{13} \mathrm{C} \mathrm{CP}$ with contact time of $2000 \mu \mathrm{s}$, (b-iii) dipolar dephasing with contact time of $1000 \mu \mathrm{s}$ and delay times, $d=60,20,10,0 \mu \mathrm{s}$. When delay times are varied in the dipolar dephasing experiment, different $\mathrm{C}$ functional groups can be identified based on their attenuation rates. See Supporting Information for ssNMR pulse sequence details. Spectra were acquired with $10 \mathrm{kHz}$ MAS at $500 \mathrm{MHz}$ (b-i, b-ii) and $700 \mathrm{MHz}$ (a-i, a-ii, a,b-iii) and are scaled by maximum intensity. All of the experiments were measured on samples prepared with deuterated naphthalene with the exception of (a-ii). Additional experiments confirm the residual naphthalene assignment and are available in the Supporting Information.

3b-i) show a similar spectral signature to the FEC precipitate, but with additional resonances A, B, G, H, and I detected. Note that the ssNMR spinning sideband (from the deuterated naphthalene, labelled D-Napth.) shifts in the spectrum, compared to the FEC precipitate, as it was acquired at a different field strength. Resonance A (179 ppm) is characteristic of a carboxyl $\mathrm{RCO}_{2} \mathrm{Li}$ environment. Given that the distinctive ${ }^{1} \mathrm{H}$ shift of $\mathrm{HCO}_{2} \mathrm{Li}$ was detected in the ${ }^{1} \mathrm{H}$ ssNMR spectrum of the $\mathrm{VC}$ precipitate, the signal is assigned to $\mathrm{HCO}_{2} \mathrm{Li}$. $\mathrm{CH}_{3} \mathrm{CH}_{2} \mathrm{CO}_{2} \mathrm{Li}$, if present, would also contribute to the signal. The overlapping carbonate resonances $\mathrm{B}(172 / 170 \mathrm{ppm})$ are assigned to $\mathrm{Li}_{2} \underline{C}_{2} \mathrm{O}_{4}$ and $\mathrm{Li}_{2} \underline{\mathrm{CO}_{3}}$, respectively. The resonance $\mathrm{G}$ (36 ppm) is assigned to a distribution of $\mathrm{R} \underline{C} \mathrm{H}_{2} \mathrm{R}$ ' environments. The minor peak $\mathrm{H}(20 \mathrm{ppm})$ is characteristic of $\mathrm{CH}_{3} \underline{\mathrm{C}} \mathrm{H}_{2} \mathrm{R}$, or alternatively a $\mathrm{CH}_{3} \mathrm{CH}-$ group adjacent to an $\mathrm{O}$ as indicated in Table 2. The minor peak I (13 ppm) is characteristic of $\mathrm{CH}_{3} \mathrm{R}$ environments; the resonance likely has some contribution from residual diethyl ether $\left(\mathrm{CH}_{3} \mathrm{CH}_{2}-\mathrm{O}-\mathrm{CH}_{2} \mathrm{CH}_{3}\right)$ used to rinse the precipitates during synthesis. However, reactions forming these environments in minor quantities may also contribute to the signal.

The ${ }^{7} \mathrm{Li}^{13} \mathrm{C}$ cross polarization experiment (Figure 3bii) indicates the $\mathrm{Li}^{+}$coordination environments by the carboxyl and carbonate groups. The broad resonance of $\mathrm{A}$ is consistent with the $\mathrm{HCO}_{2} \mathrm{Li}$ assignment. The majority of the signal contributing to the asymmetric peak at $\mathrm{B}$ is assigned to $\mathrm{Li}_{2} \underline{\mathrm{CO}_{3}}$, the small shoulder being assigned to $\mathrm{Li}_{2} \underline{C}_{2} \mathrm{O}_{4}$. The ${ }^{7} \mathrm{Li}$ ssNMR spectra are consistent with these assignments (Figure 2).

Table 2: ${ }^{13} \mathrm{C}$ ssNMR assignment for peaks A-I labelled in Figure 3.

\begin{tabular}{|c|c|c|}
\hline Resonance & Shift/ppm & Fragment \\
\hline$\overline{\mathrm{A}: \mathrm{VC}}$ & 179 & $\mathrm{H}_{\underline{C}} \mathrm{O}_{2} \mathrm{Li}$ \\
\hline B: $\mathrm{VC}$ & $170 / 172$ & $\mathrm{Li}_{2} \underline{C} \mathrm{O}_{3} / \mathrm{Li}_{2} \underline{C}_{2} \mathrm{O}_{4}$ \\
\hline C: VC/FEC & 155 & $\mathrm{RO} \underline{\underline{C}} \mathrm{O}_{2} \mathrm{R}$ \\
\hline D: VC/FEC & 100 & $-\underline{\mathrm{CH}^{\prime}}-$ \\
\hline E: VC/FEC & 74 & $\underline{\mathrm{C}} \mathrm{H}-\mathrm{O}-$ \\
\hline F: FEC & 40 & $\mathrm{R} C \mathrm{H}_{2} \mathrm{R}^{\prime}$ \\
\hline G: VC & 36 & $\mathrm{R} \underline{C} \mathrm{H}_{2} \mathrm{R}^{\prime}$ \\
\hline $\mathbf{H}$ : VC & 20 & $\mathrm{CH}_{3} \underline{\bar{C}} \mathrm{H}_{2} \mathrm{R}$ or \\
\hline I: $\mathrm{VC}$ & 13 & $\begin{array}{l}\mathrm{CH}_{3} \mathrm{CH}^{\prime} \\
\underline{\mathrm{C}} \mathrm{H}_{3} \mathrm{R}\end{array}$ \\
\hline
\end{tabular}

In the dipolar dephasing experiment (Figure 3b-iii), the carbonate resonances $\mathrm{B}$ (assigned to $\mathrm{Li}_{2} \mathrm{CO}_{3}$ and $\mathrm{Li}_{2} \underline{C}_{2} \mathrm{O}_{4}$ ), which do not have directly bonded protons, are not attenuated in the experiment. In contrast resonances $\mathrm{D}, \mathrm{E}$, and $\mathrm{G}$ show pronounced attenuation, at similar rates of decay (with increased dephasing times), 
indicating $\mathrm{CH}$ and $\mathrm{CH}_{2}$ groups, confirming the protonated $\mathrm{C}$ assignments (Table 2). The two sharp resonances $\mathrm{H}$ (at the same position as a naphthalene spinning sideband, as indicated by an asterisk), and I show signal attenuation consistent with their assignments in Table 2, the $\underline{\mathrm{C}} \mathrm{H}_{3} \mathrm{R}$ environment being expected to attenuate more slowly. The Supporting Information contains a ${ }^{1} \mathrm{H}-{ }^{13} \mathrm{C} \mathrm{CP}$ spectrum, performed at lower field, which helped separate the isotropic resonances and sidebands and confirmed the presence of peaks $\mathrm{H}$ and I. No significant attenuation of resonance $\mathrm{A}$ is seen in the dipolar dephasing experiment (Figure 3b-iii), which is not consistent with its assignment solely to $\mathrm{HCO}_{2} \mathrm{Li}$. This spectrum was collected at a higher magnetic field strength than the spectra shown in Figure 3b (i) and (ii) and there is now a severe overlap with the now much more intense D-Napth. spinning sideband, (labelled with an asterisk), this signal not being attenuated in the dephasing experiment. Similarly no attenuation is expected for an acetate resonance.

FTIR. FTIR spectra of the precipitates obtained on reduction of FEC and VC are displayed in Figure 4, confirming chemically bonded groups assigned in our XPS and ssNMR spectra. Our assignment here is based on comparison of the spectra to related studies. ${ }^{18,32,44,47}$ The FEC and VC reduction products have similar FTIR signatures, with some relative intensity differences at approximately $1300,1400-1500$, and $1750 \mathrm{~cm}^{-1}$. In addition to the VC/FEC reduction products, some residual naphthalene is seen $\left(788,3064 \mathrm{~cm}^{-1}\right)$. In each of the samples, the previously assigned $\mathrm{Li}_{2} \mathrm{CO}_{3}$ is again observed $\left(878 \mathrm{~cm}^{-1}, 1449 \mathrm{~cm}^{-1}\right.$ and $\left.1488 \mathrm{~cm}^{-1}\right)$. As also seen by ${ }^{13} \mathrm{C}$ ssNMR (Figure $3 \mathrm{~b}$-ii) and the C1s XPS spectra (Figure 1), the $\mathrm{Li}_{2} \mathrm{CO}_{3}$ is more prevalent in the VC sample.

In the FEC reduction product, peaks for carbonate $\mathrm{C}=\mathrm{O}\left(1795 \mathrm{~cm}^{-1}\right)$ and $\mathrm{C}-\mathrm{O}\left(1080,1171 \mathrm{~cm}^{-1}\right)$ bonds are seen. These peaks are assigned to bonds contained in $\mathrm{ROCO}_{2} \mathrm{R}$ environments, resembling those assigned to a poly(VC) product in our previous study. ${ }^{18}$ Peaks for carboxylate $\mathrm{C}=\mathrm{O}\left(1598 \mathrm{~cm}^{-1}\right)$ and $\mathrm{C}-\mathrm{O}\left(1402 \mathrm{~cm}^{-1}\right)$ bonds are also seen, these absorptions being consistent with a mixture of $\mathrm{HCO}_{2} \mathrm{Li}$ and/or $\mathrm{Li}_{2} \mathrm{C}_{2} \mathrm{O}_{4} \cdot{ }^{44}$ In the $\mathrm{VC}$ reduction product, similar peaks for carbonate $\mathrm{C}=\mathrm{O}$ $(1793 \mathrm{~cm}-1)$ and $\mathrm{C}-\mathrm{O}\left(1077,1172 \mathrm{~cm}^{-1}\right)$ bonds and carboxylate $\mathrm{C}=\mathrm{O}\left(1619 \mathrm{~cm}^{-1}\right)$ and $\mathrm{C}-\mathrm{O}\left(1428 \mathrm{~cm}^{-1}\right)$ bonds are assigned to poly $(\mathrm{VC})$ and $\mathrm{HCO}_{2} \mathrm{Li}^{-} \mathrm{Li}_{2} \mathrm{C}_{2} \mathrm{O}_{4}$, respectively. Recall that the signature for $\mathrm{HCO}_{2} \mathrm{Li}$ was also seen in the ${ }^{1} \mathrm{H}$ and ${ }^{13} \mathrm{C}$ ssNMR (Figures 2 and 3 ) and XPS C1s (Figure 1) spectra. With $\mathrm{HCO}_{2} \mathrm{Li}$ only being detected in the $\mathrm{VC}$ sample by ssNMR, and the stronger peak intensity at $1660 \mathrm{~cm}^{-1}$ in the VC precipitate, the $\mathrm{HCO}_{2} \mathrm{Li}$ likely resonates at the higher frequency of $1660 \mathrm{~cm}^{-1}$ and $\mathrm{Li}_{2} \mathrm{C}_{2} \mathrm{O}_{4}$ at a lower frequency of $1600 \mathrm{~cm}^{-1}$.

To gain further insight into the decomposition mechanisms, an additional experiment was performed with a half molar equivalent of Li-Nap, providing FTIR spectra comparable to that of Figure 4 (see Supporting Infor-

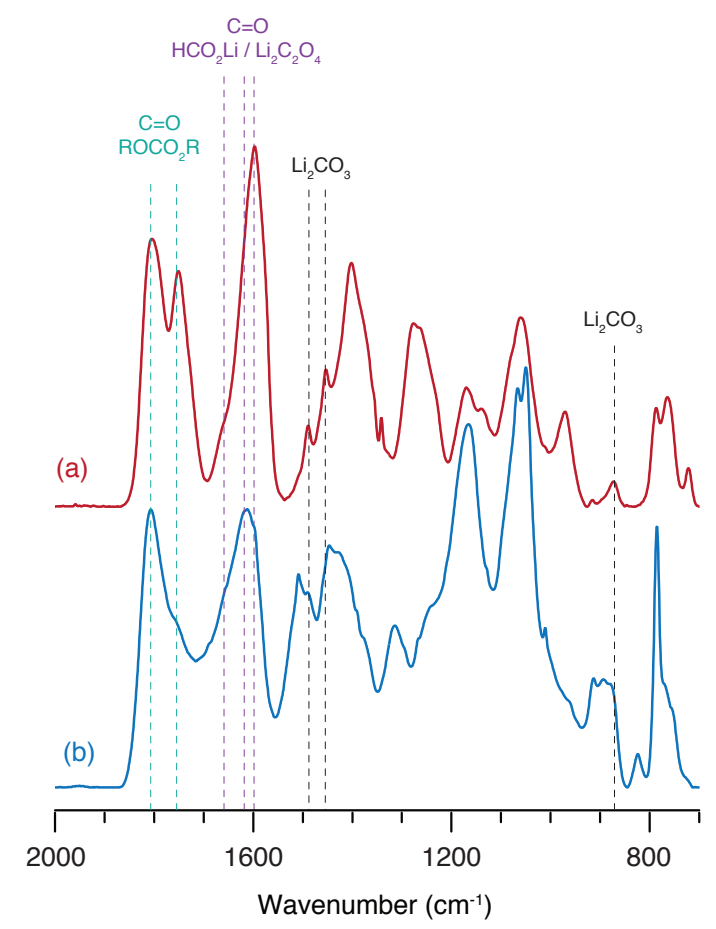

Figure 4: FTIR spectra of the precipitates obtained through reduction of (a) FEC and (b) VC using non-deuterated naphthalene.

mation). The spectra show much weaker intensities for the peaks assigned to $\mathrm{Li}_{2} \mathrm{CO}_{3}, \mathrm{Li}_{2} \mathrm{C}_{2} \mathrm{O}_{4}$, and $\mathrm{HCO}_{2} \mathrm{Li}$, relative to the peaks assigned to $\mathrm{ROCO}_{2} \mathrm{R}$ environments assigned to poly $(\mathrm{VC})$, revealing a $\mathrm{Li}$ concentration dependence in the formation of these inorganics.

GC-MS analysis of gases. GC-MS analysis was performed, providing more insight for the reduction mechanisms of FEC and VC, resulting in the solid precipitates. For FEC, the reduction with Li-Nap yields a mixture of $\mathrm{CO}$ and $\mathrm{CO}_{2}$. The ratio of $\mathrm{CO}$ to $\mathrm{CO}_{2}$ peak areas is 1:4.4. For VC, the reduction with Li-Nap yielded carbon monoxide as the only gaseous product (i.e. no $\mathrm{CO}_{2}$ was detected), $\mathrm{CO}_{2}$ having been detected previously. ${ }^{45,47}$ The absence of $\mathrm{CO}_{2}$ detection was attributed to its consumption in further reactions, the experiment being performed in a closed system, with an abundance of Li.

Proposed Reduction Products. Based on the above analysis, we propose that the reduction product poly $(\mathrm{VC})$ is present in the precipitates of both FEC and $\mathrm{VC}$, as well as $\mathrm{Li}_{2} \mathrm{C}_{2} \mathrm{O}_{4}, \mathrm{Li}_{2} \mathrm{CO}_{3}$, and $\mathrm{HCO}_{2} \mathrm{Li}$, Figure 5. The relative ratio of these products differs for $\mathrm{VC}$ and FEC.

The $\mathrm{RO} \underline{C} \mathrm{O}_{2} \mathrm{R}$ environment assigned in each of the XPS, ssNMR (Table 2, fragment C), and FTIR spectra is assigned to the repeating $\mathrm{EC}$ units of the poly $(\mathrm{VC})$. The C-O environments seen by XPS and corresponding protonated $\mathrm{C}$ environments adjacent to one $\mathrm{O}$ seen by ${ }^{13} \mathrm{C}$ ssNMR (Table 2 , fragment $\mathrm{E}$ ) are also assigned to the repeating EC units of poly $(\mathrm{VC})$. The repeating $\mathrm{EC}$ units of the poly $(\mathrm{VC})$ may terminate with a $\mathrm{CH}_{3}$ group and contribute to the ${ }^{13} \mathrm{C}$ ssNMR signal of resonance $\mathrm{H}$ (Table 2 ). ${ }^{13} \mathrm{C}$ ssNMR resonance $\mathrm{D}$, as- 


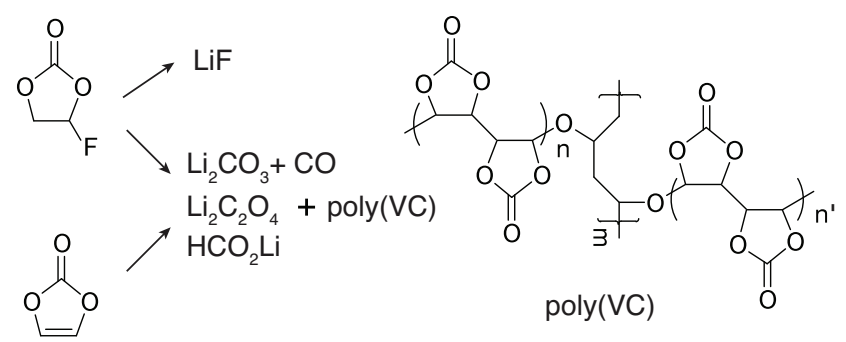

Figure 5: Proposed FEC/VC reduction products. A possible structure for a crosslinking site of poly $(\mathrm{VC})$ is indicated.

signed to protonated $\mathrm{C}$ environments adjacent to two OR groups, indicates the possibility of a crosslinking site for poly(VC) (seen in Figure 5). The crosslinking site may also contain $\mathrm{C}$ environments adjacent to one $\mathrm{O}$, contributing to resonance $\mathrm{E}$. The signals from the distribution of carbons not adjacent to $\mathrm{O}$ (Table 2, fragments $\mathrm{F}-\mathrm{I}$ ) are assigned to the crosslinking site; the assignment for these peaks would vary according to the crosslinking terminations. Note that the broad peaks of the ${ }^{13} \mathrm{C}$ ssNMR spectra (Figure 3 ) indicate a distribution of local environments. A labelled structure and calculated ${ }^{13} \mathrm{C}$ and ${ }^{1} \mathrm{H}$ NMR chemical shifts of the proposed poly $(\mathrm{VC})$ structure that support the assignment are included in the Supporting Information (Figures S4-S6). Additional structures with similar functional groups, that are consistent with the NMR chemical signatures and assigned fragments (Table 2) cannot be ruled out completely. Note that while the direct excitation ${ }^{13} \mathrm{C}$ ssNMR spectra is a quantitive result (Figure 3-i), an accurate deconvolution was not attainable due to combined factors of weak resonances, strong background signal, and the presence of residual solvents.

\section{Discussion}

Overall, our ssNMR, XPS, and FTIR experiments show complementary evidence for the presence of poly (VC) in the reduction products of both FEC and VC (possible reactions in Scheme 1-i, ii). While similar species were seen in each of the precipitates, a clear difference was seen with respect to the relative quantities of inorganic $\mathrm{Li}$ environments. In particular, we detected $\mathrm{HCO}_{2} \mathrm{Li}$, $\mathrm{Li}_{2} \mathrm{C}_{2} \mathrm{O}_{4}$ and $\mathrm{Li}_{2} \mathrm{CO}_{3}$ in higher concentrations in the VC precipitate than in the FEC precipitate. For the FEC precipitate, the majority of $\mathrm{Li}$ was contained in $\mathrm{LiF}$, with the relative quantities of the $\mathrm{Li}$ environments being confirmed by the quantitative ${ }^{7} \mathrm{Li}$ ssNMR spectrum (Figure 2). Definitive assignments for C-groups and fluorinated-species contained in the reduction products were aided by the large chemical shift dispersion of the ${ }^{13} \mathrm{C}$ and ${ }^{19} \mathrm{~F}$ ssNMR spectra. The large chemical shift dispersion in the ssNMR spectra was complementary to the XPS analysis, which had higher sensitivity but contained overlapping peaks in the spectra. By ssNMR, the detection of the carboxylate environments were only observed in the $\mathrm{VC}$ precipitate (not the FEC precipitate), this result attributed to the small concentrations of the carboxylate environments in the
FEC precipitate. A difference in sensitivity between the samples was supported by a relative elemental analysis provided by XPS (see Table 1), showing smaller relative quantities of species containing $\mathrm{C}$ and $\mathrm{O}$ in the $\mathrm{FEC}$ precipitate than the $\mathrm{VC}$ precipitate. In contrast, carbonate resonances were seen in both the $\mathrm{VC}$ and FEC precipitate by ssNMR, supporting the presence of poly $(\mathrm{VC})$ in each of the samples (the proposed poly $(\mathrm{VC})$ structure containing repeating EC units and a cross linking site, Figure 5). The carboxylate and carbonate assignments in the ${ }^{13} \mathrm{C}$ ssNMR and C1s/O1s XPS spectra were further supported by the detection of these chemical bonds in the FTIR spectra.

We note that the results in this study only show the presence of an LiF fluorine environment, contradicting the results in previous XPS studies where additional organo-fluoride environments were seen and attributed to the reduction of FEC; for example, Etacheri et al. observed a central $\mathrm{F} 1 \mathrm{~s}$ peak assigned to $\mathrm{LiF}$ at approximately $685 \mathrm{eV}$ and organic fluorides at approximately $688 \mathrm{eV} .{ }^{29}$ Our XPS result shows a single resonance assigned to LiF, with no clear shoulder in the spectra. Our ${ }^{19} \mathrm{~F}$ ssNMR results, which have the advantage of a larger chemical shift dispersion, are in agreement with our XPS results. Moreover, we have performed ${ }^{19} \mathrm{~F}-{ }^{13} \mathrm{C}$ ssNMR cross polarization experiments and have not detected any signal in the region where $\mathrm{C}-\mathrm{F}$ bonds would be expected in the ssNMR spectrum (Figure 3a-ii). In addition, we have also not seen any evidence for volatile fluorine-containing hydrocarbons by GC-MS.

Proposed Reduction Mechanisms. Possible reaction schemes to form the products proposed on the basis of the experimental data are outlined in Scheme 1-i, ii, and iii. We stress that there are likely multiple competing pathways and viable reactions also leading to reduction products with similar chemical signatures.

For the reduction of VC, Scheme 1-i, a possible first step of the reaction is the reduction of $\mathrm{VC}$ to generate a radical anion followed by loss of $\mathrm{CO}_{2}$ and generation of the vinyloxy radical anion. The vinyloxy radical anion could initiate the polymerization of $\mathrm{VC}$ but more likely scavenges $\mathrm{H}^{+}$to generate the vinyloxy radical which has been reported as the intermediate species in the FEC reduction by Shkrob et al. ${ }^{53}$ The reactive vinyloxy radical can initiate the polymerization of $\mathrm{VC}$ to generate poly $(\mathrm{VC})$ via a radical polymerization reaction. The presence of the residual vinyl group from the vinyloxy radical can then polymerize via a radical polymerization mechanism to generate the crosslinked polymer.

With the reduction products detected being nearly identical to FEC, the difference being the LiF product, similar reduction mechanisms are expected. One possible mechanism for the reaction of FEC is nearly identical to the reaction of $\mathrm{VC}$, except that the first step of the reaction involves the reduction of FEC to generate $\mathrm{VC}, \mathrm{LiF}$, and $1 / 2 \mathrm{H}_{2}$, Scheme 1 -ii. We note that $\mathrm{LiF}$ was generated nearly quantitatively via the Li-Nap reduction of FEC in our experiments. While we were unable to observe $\mathrm{H}_{2}$ generation, as the mass of $\mathrm{H}_{2}$ is 

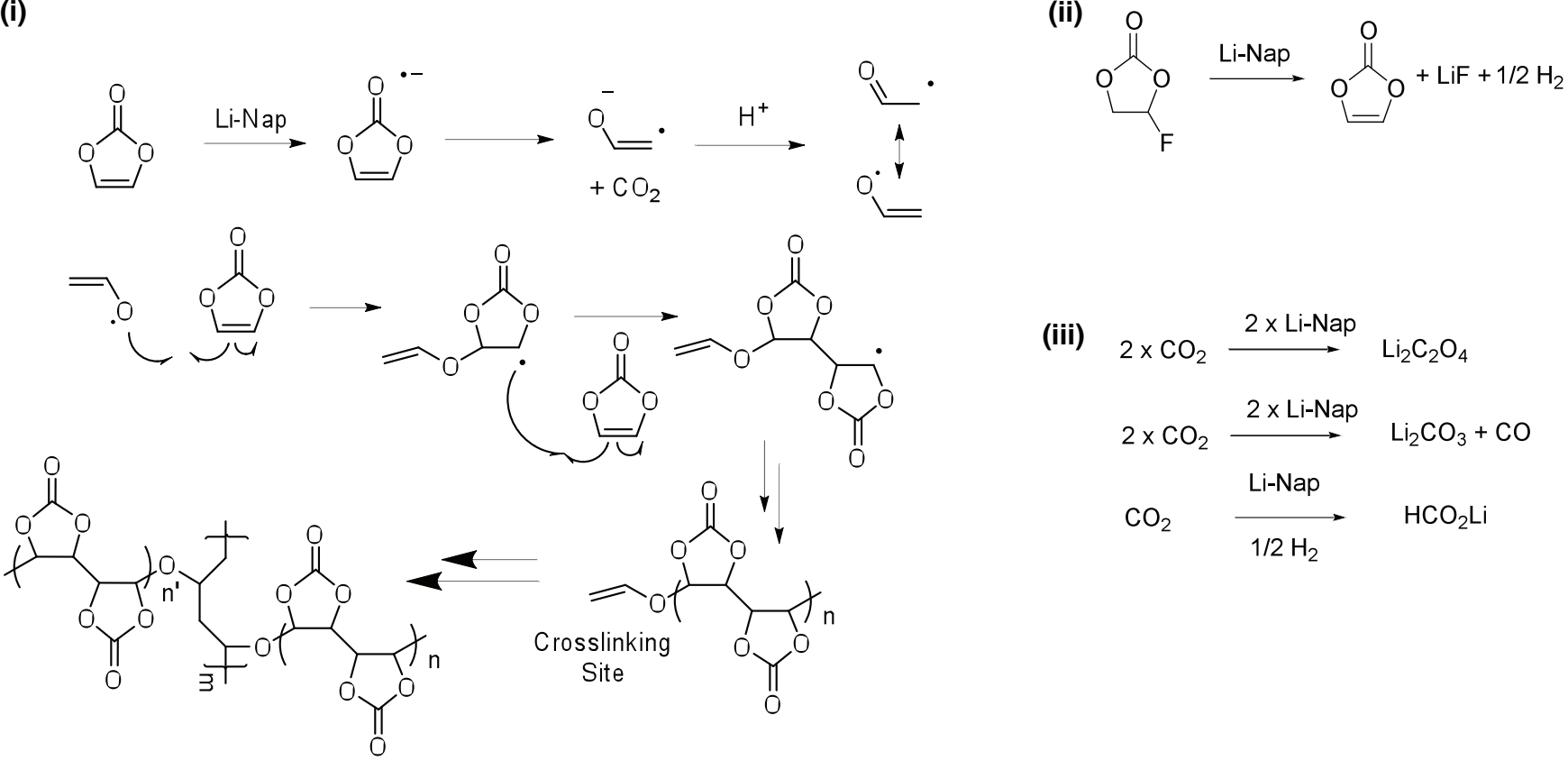

Scheme 1: Possible reaction schemes consistent with the chemical signatures detected by XPS, ssNMR, FTIR, and GC-MS.

below the detection limit of our GC-MS, the detection of $\mathrm{H}_{2}$ during the reduction of FEC was previously reported as part of the 4 electron reduction mechanism of FEC by Jung et al. ${ }^{54}$ The rapid polymerization of the VC generated from FEC can be explained by VC being more reactive under the reductive conditions than FEC. Additional experiments to confirm the FEC reduction mechanism were performed; when the Li-Nap reduction of FEC was conducted under very dilute conditions, with a large excess of FEC, trace quantities of $\mathrm{VC}$ (in addition to the previously reported products) were observed, supporting the reductive conversion of FEC to VC. The reaction mixtures obtained from reduction of dilute FEC with lithium naphthalenide contain a new peak in the GC trace at $3.10 \mathrm{~min}$. The MS of the new peak matches the MS in the NIST library for VC (see Supporting Information). The intensity of the VC peak increased with decreasing FEC concentration: when the FEC concentration was $0.134 \mathrm{M}$, the intensity of the VC peak was $1.0 \times 10^{4}$ (total ion current); after the concentration of FEC decreased to $0.055 \mathrm{M}$, the intensity of the $\mathrm{VC}$ peak increased to $1.1 \times 10^{5}$ (total ion current). The systematic increase in the VC concentration, with a decrease in the FEC concentration, is consistent with the trapping of a reactive intermediate. Interestingly, when 0.5 equivalents of $\mathrm{Li}$-Nap were reacted with FEC, only 0.5 equivalents of FEC were reduced; in contrast, addition of 0.5 equivalents of Li-Nap to VC resulted in the reduction of all of the VC. These observations are consistent with a stoichiometric reduction of FEC and a catalytic reduction of $\mathrm{VC}$. We also note that the approximate $2: 1$ ratio of $\mathrm{CO}_{2}$ to $\mathrm{H}_{2}$ previously observed by Jung et al. ${ }^{54}$ correlates well with our proposed mechanisms in (i) and (ii). Further work is ongoing to explore the reduction mechanisms in greater detail.

We note that Shkrob et al., ${ }^{53}$ have detected the vinyloxy radical in our proposed reaction Scheme 1$\mathrm{i}$ in their radiolysis experiments and have concluded that the single-electron reaction of $\mathrm{FEC}+\mathrm{Li}+\mathrm{e}^{--} \rightarrow$ $\mathrm{LiF}+\mathrm{CO}_{2}+\mathrm{CH}_{2} \mathrm{CHO}$ is viable. However, the reaction is inconsistent with our observation of a VC intermediate and the observation of $\mathrm{H}_{2}$ evolution by Jung et al. ${ }^{54}$ In addition, the absence of $\mathrm{C}-\mathrm{F}$ environments detected in our study (albeit on chemically reduced FEC) contradicts subsequent reactions they have proposed. We note however that the conditions by which reduction occurs - radiolysis vs chemical reduction may result in different reaction products.

Comparison with SEI studies. Our results show strong similarities to previous SEI studies where these additives have been used in the electrolyte of cycled cells, the similarities validating the technique of using the naphthalene reduced products as a model to study the SEI formed in Li-ion cells. For example, in a study by Ouatani et al., ${ }^{21}$ the degradation of $\mathrm{VC}$ was analyzed by using XPS analysis of $\mathrm{LiCoO}_{2} /$ graphite electrodes prepared in a Li-ion cell with $\mathrm{LiPF}_{6}$ in $1 \mathrm{~mol} \mathrm{~L}^{-1}$ pure $\mathrm{VC}$ electrolyte. Their C1s XPS spectra showed degradation products at $291.3 \mathrm{eV}\left(\mathrm{CO}_{3}\right), 287.8 \mathrm{eV}\left(\mathrm{CO}_{2}\right)$, and $\sim 286.6 \mathrm{eV}(\mathrm{CO})$, the peak positions agreeing with those observed in this study. Here, we have assigned the $\mathrm{VC}$ degradation products to poly $(\mathrm{VC})(291.0 \mathrm{eV}$ and $286.8 \mathrm{eV})$ and $\mathrm{HCO}_{2} \mathrm{Li} / \mathrm{Li}_{2} \mathrm{C}_{2} \mathrm{O}_{4}(288.5 \mathrm{eV})$, the latter assignment being supported by our ${ }^{13} \mathrm{C}$ ssNMR results. We note that the differences in intensity for the peaks at 290 and $287.8 \mathrm{eV}$ for our data compared with that of Ouatani et al., are likely due to differences in the concentration of the $\mathrm{CO}_{2}$ reduction products $\left(\mathrm{Li}_{2} \mathrm{CO}_{3}\right.$, 
$\mathrm{HCO}_{2} \mathrm{Li}$ and $\left.\mathrm{Li}_{2} \mathrm{C}_{2} \mathrm{O}_{4}\right)$ under the conditions of their experiments compared to the conditions of our experiments (reactions in a Li-ion cell versus a closed system with an abundance of $\mathrm{Li}$ ). In another example, Ota et al. have used FTIR to analyze VC-derived SEI layers formed on graphite in Li half-cells, ${ }^{47}$ including cells prepared with $1 \mathrm{~mol} \mathrm{dm}^{-3} \mathrm{LiPF}_{6} /$ pure VC electrolyte. Their spectrum showed absorption peaks assigned to poly(VC) $\left(1817,1147,1080,758 \mathrm{~cm}^{-1}\right)$, carboxylates $\left(1580,1413 \mathrm{~cm}^{-1}\right)$, and carbon double bonds $(1620,972$ $\left.\mathrm{cm}^{-1}\right)$. The absorption peaks strongly resemble those seen in the VC reduction product in this study. However, carbon double bonds were not detected in large quantities in our VC reduction products by any of our spectroscopy analysis, ruling out the presence of unsaturated lithium alkyl dicarbonate salts such as lithium vinylene dicarbonate (LVD), and lithium divinylene dicarbonate (LDVD), these SEI decomposition products being suggested by prior theoretical investigations (see Supporting Information for our estimated NMR shifts of these predicted products). ${ }^{20}$ They observed similar ${ }^{13} \mathrm{C}$ NMR peaks at $\sim 154$, and $\sim 70-80 \mathrm{ppm}$ in ${ }^{13} \mathrm{C}$ liquid NMR spectra of the SEI formed on the graphite electrode, dissolved in DMSO-d6, which they assigned to an oligomer of $\mathrm{VC}$ and/or poly(VC), the poly(VC) assignment in agreement with the ssNMR results here (see Table 2, peaks C, E); they also observed the distinctive ${ }^{13} \mathrm{C}$ ssNMR resonance at $\sim 100 \mathrm{ppm}$, seen in this study (see Table 2, peak D) which they assigned to an oligomer of VC. Here, we have assigned the $100 \mathrm{ppm}$ resonance to a crosslinking site of poly $(\mathrm{VC})$ (see Scheme 1-i, Figure 5). We have also observed broad peaks at 36 and $40 \mathrm{ppm}$, indicating a distribution of $\mathrm{RCH}_{2} \mathrm{R}$ ' environments (see Table 2 , peaks F, G), assigned to the crosslinking site. Finally, in our previous study of the $\mathrm{SEI}$ composition on $\mathrm{Si}$ anodes formed in the presence of FEC and VC additives, ${ }^{18}$ we have observed an FTIR adsorption peak at $\sim 1800 \mathrm{~cm}^{-1}$ increasing with additive concentration, the adsorption peak being assigned to poly( $\mathrm{VC})$, as in this study.

The absence of the production of $\mathrm{CO}_{2}$ during the reduction of VC, seen by GC-MS, is in contrast to the literature. For example, the study by Ota et al., ${ }^{47}$ which used pure $\mathrm{VC}$ as an electrolyte solvent, observed $\mathrm{CO}_{2}$ as the major gaseous product and a small amount of CO. Similarly, $\mathrm{CO}_{2}$ has been reported as the major gaseous product, when $\mathrm{VC}$ is used as an electrolyte additive. ${ }^{45,49}$ The discrepancy is likely due to the reduction of $\mathrm{CO}_{2}$ by excess $\mathrm{Li}$ napthalanide to generate $\mathrm{CO}$, $\mathrm{Li}_{2} \mathrm{CO}_{3}$, and $\mathrm{Li}_{2} \mathrm{C}_{2} \mathrm{O}_{4}$ (see Scheme 1-iii). ${ }^{55}$ In the reduction of FEC, most of the Li-Nap is consumed to convert FEC to $\mathrm{VC}$ and $\mathrm{LiF}$ (see Scheme 1-ii). Thus there is less residual Li-Nap present to reduce the $\mathrm{CO}_{2}$ (Scheme 1-iii), resulting in the mixture of $\mathrm{CO}$ and $\mathrm{CO}_{2}$ measured by GC-MS in a ratio of 1:4.4, respectively. In contrast, $\mathrm{VC}$ is directly reduced by Li-Nap and thus there is excess Li-Nap present to reduce all of the $\mathrm{CO}_{2}$ to $\mathrm{CO}$ (Scheme 1-iii), resulting in more $\mathrm{Li}_{2} \mathrm{CO}_{3}$ in the $\mathrm{VC}$ precipitate compared with the FEC precipitate. The in- creased concentration of $\mathrm{Li}_{2} \mathrm{CO}_{3}$ in the $\mathrm{VC}$ precipitate was observed by XPS, ssNMR, and FTIR (Figures 1, 3, and 4). Furthermore, additional experiments (see Supporting Information) showed that decreasing to a half molar Li-Nap concentration decreased the FTIR peak intensities of $\mathrm{Li}_{2} \mathrm{CO}_{3}, \mathrm{Li}_{2} \mathrm{C}_{2} \mathrm{O}_{4}$, and $\mathrm{HCO}_{2} \mathrm{Li}$, relative to the peaks assigned to poly $(\mathrm{VC})$, indicating decreased reduction of $\mathrm{CO}_{2}$ (by the reactions of Scheme 1-iii).

While this study does not show the reduction reactions on an anode in a Li-ion cell, the chemical signatures of the reduction products seen here may serve as a useful reference for future studies where an SEI has been formed in a Li-ion cell in the presence of FEC and VC. We acknowledge that reactions in the cell may differ due to many factors such as the presence of additional co-solvents and the reactivity at the surface of the lithiated anode; under these considerations, it is interesting to reflect on the practical use of these additives in the context of the results here. FEC and VC have been shown to improve $\mathrm{Si}$ electrode capacity retention, ${ }^{5,12,13,16-18,29} \mathrm{Si}$ systems suffering from uncontrolled SEI growth due to the large volume expansion of the Si particles during lithiation, thought to result in cracking in the SEI. ${ }^{52}$ The poly(VC) formed by each of these additives would likely aid SEI elasticity helping to solve the problem. However, elasticity is not the only design requirement; $\mathrm{Li}^{+}$transport across the SEI to access the Si particles during electrochemical cycling is also critical. Therefore, increasing the polymer content may not be an adequate solution if the resulting SEI cannot facilitate transport. Grain boundaries and the mixture of polymerized chains with inorganic products may for example play a role in $\mathrm{Li}^{+}$transport across the SEI. With improved capacity retention being achieved by using FEC in higher concentrations vs VC (10-25 wt\% FEC and 3-6 wt \% VC in our previous study ${ }^{18}$ ) the relative mix of inorganics and organics may be an important SEI design parameter to consider. These results suggest that more $\mathrm{FEC}$ is required to form the same amount of poly $(\mathrm{VC})$; further work is ongoing to explore these ideas.

\section{Conclusions}

We have prepared reduction products of FEC and VC, capturing their spectral signatures by ssNMR, XPS, and FTIR. Our results indicate similar reduction products for $\mathrm{FEC}$ and $\mathrm{VC}$, but in differing relative quantities, of $\mathrm{Li}_{2} \mathrm{CO}_{3}, \mathrm{Li}_{2} \mathrm{C}_{2} \mathrm{O}_{4}, \mathrm{HCO}_{2} \mathrm{Li}$, and poly(VC). We have proposed a reaction scheme for the formation of poly $(\mathrm{VC})$, the poly $(\mathrm{VC})$ containing a crosslinking site. While the reaction scheme is a reasonable proposal it is not definitive. Additional species may also be formed and lead to similar chemical signatures.

For the case of FEC reduction, the results suggest a mechanism where FEC reduces to form $\mathrm{LiF}$ and $\mathrm{VC}$, followed by subsequent VC reduction; when monitoring the reaction under dilute conditions by GC-MS, we observed the formation of $\mathrm{VC}$ in trace quantities. Interestingly, we did not detect any fluorinated organic 
species in large enough quantities for an assignment in either of the ${ }^{19} \mathrm{~F}$ ssNMR or F1s XPS spectra. With the majority of $\mathrm{Li}$ being consumed in the formation of $\mathrm{LiF}$, only small quantities of $\mathrm{Li}_{2} \mathrm{CO}_{3}, \mathrm{Li}_{2} \mathrm{C}_{2} \mathrm{O}_{4}$, and $\mathrm{HCO}_{2} \mathrm{Li}$ were subsequently formed.

For the case of $\mathrm{VC}$ reduction, greater quantities of $\mathrm{Li}_{2} \mathrm{CO}_{3}, \mathrm{Li}_{2} \mathrm{C}_{2} \mathrm{O}_{4}, \mathrm{HCO}_{2} \mathrm{Li}$ were seen. The different relative quantities of inorganic $\mathrm{Li}$ environments in the reduction products of $\mathrm{VC}$ and $\mathrm{FEC}$ may relate to their practical use in lower and higher concentrations as electrolyte additives, the relative quantities of inorganic and organic environments of the SEI formed in the presence of these additives likely having an impact on $\mathrm{Li}^{+}$transport.

Acknowledgement This work was partially supported by the Assistant Secretary for Energy Efficiency and Renewable Energy, Office of Vehicle Technologies of the U.S. Department of Energy under Contract No. DE-AC02-05CH11231, under the Batteries for Advanced Transportation Technologies (BATT) Program subcontract \#7057154. This work was partially supported by the U.S. Department of Energy EPSCoR Implementation Award Grant DE-SC0007074 for BLL, BSP, and TY. A.L.M. is an awardee of a Schiff Foundation Studentship and a nanoDTC Associate. M.L. is an awardee of the Weizmann Institute of Science - National Postdoctoral Award for Advancing Women in Science and thanks the EU Marie Curie intra-European fellowship for funding.

Supporting Information Available: Further ssNMR experimental details and spectra, FTIR spectra, and NMR chemical shift DFT calculations. This material is available free of charge via the Internet at http://pubs.acs.org/.

\section{References}

(1) $\mathrm{Xu}, \mathrm{K}$. Nonaqueous liquid electrolytes for lithium-based rechargeable batteries. Chem. Rev. 2004, 104, 4303-4418.

(2) Abe, K.; Yoshitake, H.; Kitakura, T.; Hattori, T.; Wang, H.; Yoshio, M. Additives-containing functional electrolytes for suppressing electrolyte decomposition in lithium-ion batteries. Electrochim. Acta 2004, 49, 4613-4622.

(3) Tasaki, K.; Kanda, K.; Kobayashi, T.; Nakamura, S.; Ue, M. Theoretical studies on the reductive decompositions of solvents and additives for lithium-ion batteries near lithium anodes. J. Electrochem. Soc. 2006, 153, A2192-A2197.

(4) Zhang, S. S. A review on electrolyte additives for lithium-ion batteries. J. Power Sources 2006, 162, 1379-1394.

(5) $\mathrm{Xu}, \mathrm{K}$. Electrolytes and interphases in Li-Ion batteries and beyond. Chem. Rev. 2014, 114, 11503-11618.

(6) Peled, E. The electrochemical behavior of alkali and alkaline earth metals in nonaqueous battery systems - the solid electrolyte interphase model. J. Electrochem. Soc. 1979, 126, 2047-2051.

(7) Peled, E.; Golodnitsky, D.; Ardel, G. Advanced model for solid electrolyte interphase electrodes in liquid and polymer electrolytes. J. Electrochem. Soc. 1997, 144, L208-L210.

(8) Fong, R.; Von Sacken, U.; Dahn, J. R. Studies of lithium intercalation into carbons using nonaqueous electrochemical cells. J. Electrochem. Soc. 1990, 137, 2009-2013.

(9) Winter, M. The solid electrolyte interphase -the most important and the least understood solid electrolyte in rechargeable Li batteries. Z. Phys. Chem. 2009, 223, 1395-1406.
(10) $\mathrm{Xu}, \mathrm{K}$; von Cresce, A. Interfacing electrolytes with electrodes in Li-ion batteries. J. Mater. Chem. 2011, 21, 98499864 .

(11) Oesten, R.; Heider, U.; Schmidt, M. Advanced electrolytes. Solid State Ionics 2002, 148, 391-397.

(12) Choi, N.-S.; Yew, K. H.; Lee, K. Y.; Sung, M.; Kim, H.; Kim, S.-S. Effect of fluoroethylene carbonate additive on interfacial properties of silicon thin-film electrode. J. Power Sources 2006, 161, 1254-1259.

(13) Chen, L.; Wang, K.; Xie, X.; Xie, J. Effect of vinylene carbonate (VC) as electrolyte additive on electrochemical performance of Si film anode for lithium ion batteries. J. Power Sources 2007, 174, 538-543.

(14) Xiong, D.; Burns, J. C.; Smith, A. J.; Sinha, N.; Dahn, J. R. A high precision study of the effect of vinylene carbonate (VC) additive in Ligraphite cells. J. Electrochem. Soc. 2011, 158, A1431-A1435.

(15) Chockla, A. M.; Klavetter, K. C.; Mullins, C. B.; Korgel, B. A. Solution-grown germanium nanowire anodes for lithium-ion batteries. ACS Appl. Mater. Interfaces 2012 4, 4658-4664.

(16) Lin, Y.-M.; Klavetter, K. C.; Abel, P. R.; Davy, N. C.; Snider, J. L.; Heller, A.; Mullins, C. B. High performance silicon nanoparticle anode in fluoroethylene carbonate-based electrolyte for Li-ion batteries. Chem. Mater. 2012, 48, $7268-7270$.

(17) Ulldemolins, M.; Le Cras, F.; Pecquenard, B.; Phan, V. P.; Martin, L.; Martinez, H. Investigation on the part played by the solid electrolyte Interphase on the electrochemical performances of the silicon electrode for lithium-ion batteries. J. Power Sources 2012, 206, 245-252.

(18) Nguyen, C. C.; Lucht, B. L. Comparative study of fluoroethylene carbonate and vinylene carbonate for silicon anodes in lithium ion batteries. J. Electrochem. Soc. 2014, 161, A1933-A1938.

(19) Aurbach, D.; Gamolsky, K.; Markovsky, B.; Gofer, Y.; Schmidt, M.; Heider, U. On the use of vinylene carbonate $(\mathrm{VC})$ as an additive to electrolyte solutions for Li-ion batteries. Electrochim. Acta 2002, 47, 1423-1439.

(20) Wang, Y.; Nakamura, S.; Tasaki, K.; Balbuena, P. B. Theoretical studies to understand surface chemistry on carbon anodes for lithium-ion batteries: how does vinylene carbonate play its role as an electrolyte additive? J. Am. Chem. Soc. 2002, 124, 4408-4421.

(21) El Ouatani, L.; Dedryvere, R.; Siret, C.; Biensan, P.; Reynaud, S.; Iratçabal, P.; Gonbeau, D. The effect of vinylene carbonate additive on surface film formation on both electrodes in Li-ion batteries. J. Electrochem. Soc. 2009, 156, A103-A113.

(22) Park, S.; Heon Ryu, J.; Oh, S. M. Passivating ability of surface film derived from vinylene carbonate on tin negative electrode. J. Electrochem. Soc. 2011, 158, A498-A503.

(23) Profatilova, I. A.; Stock, C.; Schmitz, A.; Passerini, S.; Winter, M. Enhanced thermal stability of a lithiated nanosilicon electrode by fluoroethylene carbonate and vinylene carbonate. J. Power Sources 2012, 222, 140-149.

(24) Leung, K.; Rempe, S. B.; Foster, M. E.; Ma, Y.; Martinez del la Hoz, J. M.; Sai, N.; Balbuena, P. B. Modeling electrochemical decomposition of fluoroethylene carbonate on silicon anode surfaces in lithium ion batteries. J. Electrochem. Soc. 2013, 161, A213-A221. 
(25) Martínez de la Hoz, J. M.; Balbuena, P. B. Reduction mechanisms of additives on $\mathrm{Si}$ anodes of Li-ion batteries. Phys Chem Chem Phys 2014, 16, 17091-17098.

(26) Soto, F. A.; Ma, Y.; Martínez de la Hoz, J. M.; Seminario, J. M.; Balbuena, P. B. Formation and growth mechanisms of solid-electrolyte interphase layers in rechargeable batteries. Chem. Mater. 2015, 27, 7990-8000.

(27) Profatilova, I. A.; Kim, S.-S.; Choi, N.-S. Enhanced thermal properties of the solid electrolyte interphase formed on graphite in an electrolyte with fluoroethylene carbonate. Electrochim. Acta 2009, 54, 4445-4450.

(28) Schroder, K.; Alvarado, J.; Yersak, T. A.; Li, J.; Dudney, N.; Webb, L. J.; Meng, Y. S.; Stevenson, K. J. The effect of fluoroethylene carbonate as an additive on the solid electrolyte interphase on silicon lithium-Ion electrodes. Chem. Mater. 2015, 27, 5531-5542.

(29) Etacheri, V.; Haik, O.; Goffer, Y.; Roberts, G. A.; Stefan, I. C.; Fasching, R.; Aurbach, D. Effect of fluoroethylene carbonate (FEC) on the performance and surface chemistry of Si-nanowire Li-ion battery anodes. Langmuir 2012, 28 965-976.

(30) Schroder, K. W.; Celio, H.; Webb, L. J.; Stevenson, K. J. Examining solid electrolyte interphase formation on crystalline silicon electrodes: influence of electrochemical preparation and ambient exposure conditions. J. Phys. Chem. C 2012, 116, 19737-19747.

(31) Malmgren, S.; Ciosek, K.; Lindblad, R.; Plogmaker, S.; Kühn, J.; Rensmo, H.; Edström, K.; Hahlin, M. Consequences of air exposure on the lithiated graphite SEI. Electrochim. Acta 2013, 105, 83-91.

(32) Nie, M.; Chalasani, D.; Abraham, D. P.; Chen, Y.; Bose, A.; Lucht, B. L. Lithium ion battery graphite solid electrolyte interphase revealed by microscopy and spectroscopy. $J$. Phys. Chem. C 2013, 117, 1257-1267.

(33) Morcombe, C. R.; Zilm, K. W. Chemical shift referencing in MAS solid state NMR. J. Magn. Reson. 2003, 162, 479486.

(34) Apperley, D. C.; Harris, R. K.; Hodgkinson, P. Solid State NMR. Momentum Press, New York, 2012.

(35) Massiot, D.; Fayon, F.; Capron, M.; King, I.; Le Calvé, S.; Alonso, B.; Durand, J.-O.; Bujoli, B.; Gan, Z.; Hoatson, G. Modelling one- and two-dimensional solid-state NMR spectra. Magn. Reson. Chem. 2002, 40, 70-76.

(36) Thakur, R. S.; Kurur, N. D.; Madhu, P. K. Swept-frequency two-pulse phase modulation for heteronuclear dipolar decoupling in solid-state NMR. Chem. Phys. Lett. 2006, 426, 459-463.

(37) Opella, S. J.; Frey, M. H. Selection of nonprotonated carbon resonances in solid-state nuclear magnetic resonance. J. Am. Chem. Soc. 1979, 101, 5854-5856.

(38) Frisch, M. J. et al. Gaussian 09, Revision D.01. Gaussian Inc., Wallingford $C T \mathbf{2 0 1 3}$

(39) Lee, C.; Yang, W.; Parr, R. G. Development of the ColleSalvetti correlation-energy formula into a functional of the electron density. Phys. Rev. B 1988, 37, 785-789.

(40) Becke, A. D. Density-functional thermochemistry. III. The role of exact exchange. J. Chem. Phys. 1993, 98, 5648-5652.
(41) Krishnan, R.; Binkley, J. S.; Seeger, R.; Pople, J. A. Selfconsistent molecular orbital methods. XX. A basis set for correlated wave functions. J. Chem. Phys. 1980, 72, 650654 .

(42) Frisch, M. J.; Pople, J. A.; Binkley, J. S. Self-consistent molecular orbital methods 25. Supplementary functions for Gaussian basis sets. J. Chem. Phys. 1984, 80, 3265-3269.

(43) Dedryvere, R.; Gireaud, L.; Grugeon, S.; Laruelle, S.; Tarascon, J. M.; Gonbeau, D. Characterization of lithium alkyl carbonates by X-ray photoelectron spectroscopy: experimental and theoretical study. J. Phys. Chem. B 2005, 109, 15868-15875.

(44) Verma, P.; Maire, P.; Novák, P. A review of the features and analyses of the solid electrolyte interphase in Li-ion batteries. Electrochim. Acta 2010, 55, 6332-6341.

(45) Madec, L.; Petibon, R.; Tasaki, K.; Xia, J.; Sun, J. P.; Hill, I. G.; Dahn, J. R. Mechanism of action of ethylene sulfite and vinylene carbonate electrolyte additives in $\mathrm{LiNi}$ 1/3Mn 1/3Co 1/3O 2/graphite pouch cells: electrochemical, GC-MS and XPS analysis. Phys Chem Chem Phys 2015, 17, 27062-27076

(46) Chen, X.; Li, X.; Mei, D.; Feng, J.; Hu, M. Y.; Hu, J.; Engelhard, M.; Zheng, J.; Xu, W.; Xiao, J.; Liu, J.; Zhang, J.-G. Reduction mechanism of fluoroethylene carbonate for stable solid-electrolyte interphase film on silicon anode. ChemSusChem 2013, 7, 549-554.

(47) Ota, H.; Sakata, Y.; Inoue, A.; Yamaguchi, S. Analysis of vinylene carbonate derived SEI layers on graphite anode. $J$. Electrochem. Soc. 2004, 151, A1659-A1669.

(48) Madec, L.; Xia, J.; Petibon, R.; Nelson, K. J.; Sun, J.-P.; Hill, I. G.; Dahn, J. R. Effect of sulfate electrolyte additives on $\mathrm{LiNi} 1 / 3 \mathrm{Mn} 1 / 3 \mathrm{Co} 1 / 3 \mathrm{O} 2 /$ graphite pouch cell Lifetime: correlation between XPS surface studies and electrochemical test results. J. Phys. Chem. C 2014, 118, 2960829622 .

(49) Zhang, B.; Metzger, M.; Solchenbach, S.; Payne, M.; Meini, S.; Gasteiger, H. A.; Garsuch, A.; Lucht, B. L. Role of 1,3-propane sultone and vinylene carbonate in solid electrolyte interface formation and gas generation. J. Phys. Chem. C 2015, 119, 11337-11348.

(50) Leskes, M.; Moore, A. J.; Goward, G. R.; Grey, C. P. Monitoring the electrochemical processes in the lithium-air battery by solid state NMR spectroscopy. J. Phys. Chem. C. 2013, 117, 26929-26939.

(51) Meyer, B. M.; Leifer, N.; Sakamoto, S.; Greenbaum, S. G.; Grey, C. P. High field multinuclear NMR investigation of the SEI layer in lithium rechargeable batteries. Electrochem. Solid-State Lett. 2005, 8, A145-A148.

(52) Michan, A. L.; Divitini, G.; Pell, A. J.; Leskes, M.; Ducati, C.; Grey, C. P. Solid electrolyte interphase growth and capacity loss in silicon electrodes. J. Am. Chem. Soc. 2016, 138, 7918-7931.

(53) Shkrob, I. A.; Wishart, J. F.; Abraham, D. P. What makes fluoroethylene carbonate different? J. Phys. Chem. C 2015, 119, 14954-14964.

(54) Jung, R.; Metzger, M.; Haering, D.; Solchenbach, S.; Marino, C.; Tsiouvaras, N.; Stinner, C.; Gasteiger, H. A. Consumption of fluoroethylene carbonate (FEC) on $\mathrm{Si}-\mathrm{C}$ composite electrodes for Li-ion batteries. J. Electrochem. Soc. 2016, 163, A1705-A1716. 
(55) Zhao, Y.; Zhang, Z. Thermodynamic properties of CO2 conversion by sodium borohydride. Chem. Eng. Technol. 2014, $38,110-116$. 
Graphical TOC Entry

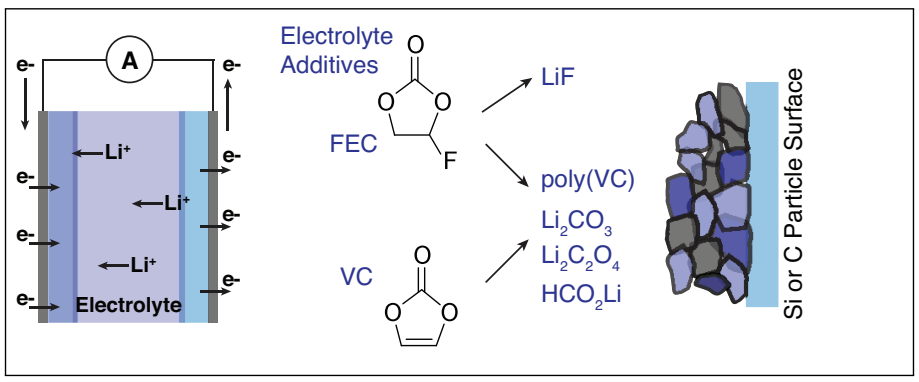

